\title{
Ag-doped ZnO nanorods synthesized on Porous Si electrode using a facile electrochemical approach for Removal of Methylene Blue from wastewater
}

$Y e Y u$

School of landscape architecture, Beijing Forestry University, Beijing 100083, China

E-mail: yeyuyy66@163.com, ye_yu@bjfu.edu.cn

doi: $10.20964 / 2020.08 .89$

Received: 4 April 2020 / Accepted: 1 June 2020 / Published: 31 December 2020

The enhanced photocatalytic features of the synthesized materials indicates their potentiality in wastewater treatment. In this work, vertically aligned silver (Ag) doped- $\mathrm{ZnO}$ nanorods (NRs) were successfully synthesized on seed-layer-free PSi structures using an electrochemical technique and FESEM results indicated that c-axis orientation was the preferential growth direction of the singlecrystalline Ag doped-ZnO NRs, consistent with XRD results. Electrochemical impedance spectroscopy (EIS) was applied to analyze the interface properties and charge transfer efficiency of samples. The removal of methylene blue as an organic compound in wastewater using the $\mathrm{Ag}$ doped-ZnO/PSi photoanodes was studied by the photoelectrocatalytic technique. The EIS results showed that Ag doped$\mathrm{ZnO} / \mathrm{PSi}$ nanostructures have higher free-electron carriers which accelerate charge transfer and decrease the resistance. The enhanced photocatalytic activity of the Ag doped-ZnO/PSi can be attributed to the enhancement of photogenerated electron-hole pairs as a result of varied potential energy between $\mathrm{ZnO}$ and $\mathrm{Ag}$.

Keywords: Ag doped-ZnO/PSi nanostructures; Electrochemical technique; Photoelectrocatalytic; Wastewater; Methylene blue

\section{$\underline{\text { FULL TEXT }}$}

(C) 2021 The Authors. Published by ESG (www.electrochemsci.org). This article is an open access article distributed under the terms and conditions of the Creative Commons Attribution license (http://creativecommons.org/licenses/by/4.0/). 